\title{
Chemical protection of oilseed rape in Poland and neighboring countries
}

\section{Chemiczna ochrona rzepaku w Polsce i krajach sąsiednich}

\author{
Ewa Matyjaszczyk ${ }^{1 *}$, Joanna Sobczak ${ }^{1}$, Hanna Adamska ${ }^{2}$
}

\section{Summary}

The paper presents data regarding the availability of products for oilseed rape chemical protection in Poland, Czech Republic, Lithuania, Germany and Slovakia in April 2017. Significant differences between countries have been observed. The most fungicides and herbicides for oilseed rape protection are registered in Czech Republic, while the highest number of insecticides in Poland. The number of active substances and chemical groups varies depending on the group of product and is the highest for fungicides and insecticides in Czech Republic. Regardless of the product group, availability of active substances, as well as their groups is the lowest in Lithuania. Products containing mixture of two or three active substances constitute about $30 \%$ of registered formulations of fungicides, about $15 \%$ of herbicides and $10 \%$ of insecticides. However, insecticides containing two active substances are not registered for oilseed rape protection in Germany. The availability of biological products for oilseed rape protection is still low. There are comparatively few products that are registered and they are not available in all countries.

Key words: active substances; availability; chemical groups; fungicides; herbicides; insecticides; plant protection; oilseed rape; registration; resistance

\section{Streszczenie}

W pracy przedstawiono dostępność środków do ochrony rzepaku w kwietniu 2017 roku w Polsce, Niemczech, Czechach, na Litwie i Słowacji. Zaobserwowano znaczne różnice pomiędzy krajami. Najwięcej fungicydów oraz herbicydów do ochrony rzepaku zarejestrowanych jest w Czechach, natomiast w Polsce najwięcej insektycydów. Liczba substancji czynnych i grup chemicznych zależy od grupy środków i dla fungicydów oraz insektycydów największa jest w Czechach. Niezależnie od grupy najmniej substancji czynnych oraz grup chemicznych dostępnych jest na Litwie. Środki zawierające mieszaninę dwóch lub trzech substancji czynnych stanowią około 30\% fungicydów, około $15 \%$ herbicydów oraz 10\% insektycydów, przy czym w Niemczech insektycydy zawierające dwie substancje czynne nie są zarejestrowane do ochrony rzepaku. Dostępność biopreparatów do ochrony rzepaku jest niewielka. Zarejestrowanych jest relatywnie niewiele produktów i nie są one dostępne we wszystkich krajach.

Słowa kluczowe: substancje czynne; dostępność; grupy chemiczne; fungicydy; herbicydy; insektycydy; ochrona roślin; rzepak; rejestracja; odporność

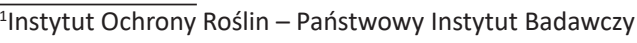

Władysława Węgorka 20, 60-318 Poznań

${ }^{2}$ Uniwersytet Przyrodniczy we Wrocławiu

pl. Grunwaldzki 24a, 50-363 Wrocław

*corresponding author: e.matyjaszczyk@iorpib.poznan.pl
} 


\section{Wstęp / Introduction}

Uprawa rzepaku ma duże znaczenie w Polsce i krajach sąsiednich. Jednym z czynników decydujących o zwiększeniu produkcji, przetwórstwa i handlu rzepakiem w ostatnich kilkunastu latach była polityka Unii Europejskiej sprzyjająca produkcji biopaliw i energii odnawialnej (Rosiak 2014). W Polsce areał uprawy tego gatunku w roku 2015 stanowił niemal 9\% ogólnej powierzchni zasiewów (GUS 2016). Powierzchnia uprawy rzepaku (wraz z rzepikiem) wynosiła w Polsce w 2016 roku 827 tys. ha. Wśrod krajów Unii Europejskiej sąsiadujących z Polską największym producentem rzepaku są Niemcy - 1,326 tys. ha. W pozostałych krajach jego areał wynosi: Czechy - 393 tys. ha, Litwa 151 tys. ha, Słowacja - 124 tys. ha (Eurostat 2017). Rzepak w dużej mierze narażony jest na szkodliwe działanie agrofagów, kilkunastu masowo występujących gatunków chwastów, kilkudziesięciu gatunków szkodników oraz kilku sprawców chorób (Jajor i Mrówczyński 2013). Założeniem obowiązującej od 2014 roku integrowanej ochrony roślin jest ograniczanie stosowania środków chemicznych do niezbędnego minimum (Barzman i wsp. 2015). W przypadku wielu agrofagów rzepaku nie ma jednak skutecznej alternatywy i stosowanie selektywnych środków chemicznych jest podstawową metodą ochrony. Należy zatem pamiętać o racjonalnym i przemiennym stosowaniu środków ochrony roślin. Ważny jest odpowiedni dobór środków posiadających różne mechanizmy działania, a żeby to było możliwe, najważniejsza jest dostępność na rynku zróżnicowanych preparatów.

Celem przeprowadzonej analizy było porównanie dostępności środków do ochrony rzepaku w Polsce i krajach sąsiednich należących do Unii Europejskiej (Niemcy, Czechy, Litwa i Słowacja).

\section{Materiały i metody / Materials and methods}

Analizę wykonano według stanu na kwiecień 2017 roku w Polsce, Niemczech, Czechach, Słowacji i na Litwie. Przeanalizowano dostępność preparatów należących do trzech głównych grup: herbicydów (w tym desykantów), fungicydów i insektycydów. W analizie nie uwzględniono mniejszych grup środków, takich jak moluskocydy czy regulatory wzrostu.

Źródłem danych były oficjalne rejestry środków ochrony roślin, dostępne na stronach internetowych instytucji odpowiedzialnych za rejestrację w poszczególnych państwach członkowskich (BVL 2017; MRiRW 2017; The State Plant Service 2017; ÚKSÚP 2017; ÚKZÚZ 2017). Rejestry przeanalizowano pod kątem dostępności zarówno samych środków ochrony roślin, jak i substancji czynnych oraz częściowo składu (tzn. czy substancje czynne występują samodzielnie, czy w mieszaninach). Substancje czynne poddano dalszej analizie pod kątem przynależności do grup chemicznych oraz mechanizmów działania. Kwalifikacji do poszczególnych grup chemicznych i mechanizmów działania dokonano na podstawie międzynarodowych baz danych (HRAC, FRAC, IRAC) oraz kompendium (The Pesticide Manual 2012).

\section{Wyniki i dyskusja / Results and discussion}

Wyniki badań dostępności agrochemikaliów w analizowanych krajach przedstawiono w tabelach 1-3. Ogółem liczba zarejestrowanych środków w poszczególnych państwach jest następująca: 233 (Niemcy), 416 (Polska), 560 (Czechy), 92 (Litwa), 221 (Słowacja). Nie zawsze większa powierzchnia uprawy danej rośliny przekłada się na większy asortyment środków ochrony roślin. Przykładowo Niemcy są krajem, w którym uprawia się najwięcej rzepaku w analizowanej grupie państw, a liczba środków zarejestrowanych do jego ochrony jest tam ponad dwukrotnie mniejsza niż w Czechach.

Przyglądając się poszczególnym grupom agrochemikaliów można zauważyć, że najwięcej insektycydów zarejestrowanych jest w Polsce. Czeski rynek z kolei najlepiej zaopatrzony jest w fungicydy i herbicydy, mimo tego, że w tym kraju areał rzepaku jest kilkukrotnie mniejszy w porównaniu z Niemcami oraz Polską. We wszystkich analizowanych krajach duży udział fungicydów oraz herbicydów stanowią formulacje zawierające dwie lub, w przypadku środków chwastobójczych, nawet trzy substancje czynne, różniące się mechanizmem działania (tab. 1, 2). W Czechach, na Litwie oraz na Słowacji odnotowano największy udział fungicydów dwuskładnikowych (ponad 35\%). Z kolei w Polsce i w Niemczech ich udział stanowił około $25 \%$. W grupie herbicydów największy udział formulacji zawierających dwie substancje czynne (około 20\%) posiadają Czechy oraz Litwa. W pozostałych krajach udział herbicydów dwu- lub trzyskładnikowych był następujący: 18\% (Słowacja), 17\% (Polska), 11\% (Niemcy). Dla insektycydów dostępność formulacji z dwiema substancjami czynnymi była niewielka i wyniosła 6\% (Słowacja), 7\% (Litwa), 8\% (Polska) i 14\% (Czechy). W Niemczech nie odnotowano dostępności na rynku insektycydów dwuskładnikowych.

Jednak sama liczba zarejestrowanych środków nie daje pełnego obrazu różnorodności na rynku ze względu na częste rejestracje tych samych środków pod różnymi nazwami handlowymi. Przeanalizowano zatem także dostępność substancji czynnych oraz grup chemicznych. Wśród fungicydów najlepszą dostępność odnotowano w Czechach. Zaraz za Czechami należy wymienić Polskę, Niemcy, Słowację, a na samym końcu Litwę (tab. 1). Liczba mechanizmów działania substancji czynnych dla poszczególnych krajów była następująca: 10 (Czechy), 9 (Polska), 8 (Niemcy, Słowacja), 4 (Litwa). Podczas analizy stwierdzono, że na 
Tabela 1. Fungicydy do ochrony rzepaku w Polsce i krajach sąsiadujących (zgodnie z danymi z kwietnia 2017)

Table 1. Fungicides for the protection of oilseed rape in Poland and neighboring countries (the data from April 2017)

\begin{tabular}{|c|c|c|c|c|c|}
\hline \multirow{2}{*}{$\begin{array}{l}\text { Substancje czynne } \\
\text { Active substances }\end{array}$} & \multicolumn{5}{|c|}{ Liczba środków - Number of products } \\
\hline & $\begin{array}{l}\text { Niemcy } \\
\text { Germany }\end{array}$ & $\begin{array}{l}\text { Polska } \\
\text { Poland }\end{array}$ & $\begin{array}{c}\text { Czechy } \\
\text { Czech Republic }\end{array}$ & $\begin{array}{l}\text { Litwa } \\
\text { Lithuania }\end{array}$ & $\begin{array}{l}\text { Słowacja } \\
\text { Slovakia }\end{array}$ \\
\hline Azoxystrobin & 17 & 17 & 23 & 3 & 1 \\
\hline Bacillus subtilis & - & - & 1 & - & - \\
\hline Boscalid & 1 & - & - & 1 & 1 \\
\hline Coniothyrium minitans & 1 & 1 & 2 & - & 2 \\
\hline Difenoconazole & 1 & 6 & 2 & 1 & 1 \\
\hline Dimethomorph & 1 & - & - & - & - \\
\hline Fluopyram & - & - & - & - & 1 \\
\hline Flutriafol & - & 1 & - & - & - \\
\hline Iprodione & - & 1 & 3 & 1 & \\
\hline Metconazole & 1 & 1 & 11 & 1 & 2 \\
\hline Picoxystrobin & 1 & 3 & 8 & 1 & 2 \\
\hline Prochloraz & 1 & 11 & - & - & - \\
\hline Prothioconazole & 1 & - & 1 & - & - \\
\hline Pythium oligandrum & - & 1 & 2 & - & 1 \\
\hline Tebuconazole & 12 & 30 & 53 & 8 & 26 \\
\hline Thiophanate-methyl & 1 & 4 & 1 & - & 1 \\
\hline Thiram & 2 & 1 & - & - & - \\
\hline Azoxystrobin + cyproconazole & - & 1 & 4 & 1 & 3 \\
\hline Azoxystrobin + tebuconazole & 1 & 2 & 2 & 1 & 2 \\
\hline Azoxystrobin + isopyrazam & 1 & 1 & 1 & - & 1 \\
\hline Boscalid + dimoxystrobin & 1 & 2 & 7 & 1 & 2 \\
\hline Boscalid + metconazole & 1 & 3 & 1 & 1 & 1 \\
\hline Carboxin + thiram & - & - & 1 & - & - \\
\hline Chlorothalonil + tetraconazole & - & 1 & 1 & - & 1 \\
\hline Cyproconazole + pikoxystrobin & - & - & 1 & - & 1 \\
\hline Difenoconazole + paklobutrazol* & 1 & 2 & 2 & 1 & 1 \\
\hline Fluopyram + prothioconazole & 1 & 1 & 1 & 1 & - \\
\hline Metconazole + mepiquat* & 1 & 1 & 2 & 1 & 2 \\
\hline Propiconazole + prochloraz & - & - & 26 & - & - \\
\hline Tebuconazole + difenoconazole & - & 2 & 1 & - & 1 \\
\hline Tebuconazole + prochloraz & 1 & 3 & - & 1 & - \\
\hline Tebuconazole + prothioconazole & 3 & 3 & 10 & 2 & 5 \\
\hline Tebuconazole + triadimenol & 1 & - & - & - & - \\
\hline Thiophanate-methyl + iprodione & 1 & 1 & 1 & - & 1 \\
\hline Thiophanate-methyl + tetraconazole & - & 3 & 1 & - & 1 \\
\hline \multicolumn{6}{|c|}{ Łącznie - Total } \\
\hline $\begin{array}{l}\text { Liczba środków } \\
\text { Number of products }\end{array}$ & 53 & 103 & 169 & 26 & 60 \\
\hline $\begin{array}{l}\text { Liczba substancji czynnych } \\
\text { Number of active substances }\end{array}$ & 17 & 20 & 22 & 12 & 17 \\
\hline $\begin{array}{l}\text { Liczba grup chemicznych } \\
\text { Number of chemical groups }\end{array}$ & 12 & 12 & 13 & 7 & 10 \\
\hline
\end{tabular}

Źródło: opracowanie własne na podstawie rejestrów środków ochrony roślin z poszczególnych krajów oraz The Pesticide Manual Source: own elaboration of plant protection products based on registered products from individual countries and The Pesticide Manual *substancja czynna o działaniu regulatora wzrostu i rozwoju roślin - active substance with the activity of a plant growth regulator 
Tabela 2. Herbicydy do ochrony rzepaku w Polsce i krajach sąsiadujących (zgodnie z danymi z kwietnia 2017)

Table 2. Herbicides for the protection of oilseed rape in Poland and neighboring countries (the data from April 2017)

\begin{tabular}{|c|c|c|c|c|c|}
\hline \multirow{2}{*}{$\begin{array}{l}\text { Substancje czynne } \\
\text { Active substances }\end{array}$} & \multicolumn{5}{|c|}{ Liczba środków - Number of products } \\
\hline & $\begin{array}{l}\text { Niemcy } \\
\text { Germany }\end{array}$ & $\begin{array}{l}\text { Polska } \\
\text { Poland }\end{array}$ & $\begin{array}{c}\text { Czechy } \\
\text { Czech Republic }\end{array}$ & $\begin{array}{c}\text { Litwa } \\
\text { Lithuania }\end{array}$ & $\begin{array}{l}\text { Słowacja } \\
\text { Slovakia }\end{array}$ \\
\hline Bifenox & 2 & 1 & - & 1 & - \\
\hline Quizalofop-p-ethyl & 6 & 19 & 15 & 4 & 8 \\
\hline Quizalofop-p-tefuryl & 1 & 2 & 3 & 1 & 2 \\
\hline Clomazone & 9 & 17 & 35 & 1 & 5 \\
\hline Clopyralid & 4 & 12 & 6 & 1 & 6 \\
\hline Cycloxydim & 1 & 1 & 2 & 1 & 2 \\
\hline Diquat & 8 & 11 & 25 & 2 & 5 \\
\hline Dimethachlor & 2 & 1 & 1 & 1 & 1 \\
\hline Ethametsulfuron-methyl & - & 3 & 1 & - & - \\
\hline Fluazifop-P-butyl & 2 & 2 & 5 & - & 1 \\
\hline Glyphosate & 76 & 57 & 92 & 22 & 29 \\
\hline Haloxyfop-P & 1 & 2 & 1 & - & 1 \\
\hline Clethodim & 1 & 2 & 4 & 1 & 1 \\
\hline Metazachlor & 3 & 23 & 18 & 3 & 12 \\
\hline Napropamide & 1 & 1 & 2 & 1 & 2 \\
\hline Pendimethalin & 2 & - & - & - & 1 \\
\hline Pethoxamid & 2 & 4 & 5 & - & 1 \\
\hline Propaquizafop & 1 & 3 & 14 & 1 & 10 \\
\hline Propyzamide & 8 & 6 & 9 & - & 1 \\
\hline S-metolachlor & - & - & - & - & 1 \\
\hline Aminopyralid + propyzamide & 1 & - & - & - & - \\
\hline Aminopyralid + clopyralid + picloram & 1 & 5 & 7 & - & 3 \\
\hline Aminopyralid + metazachlor + picloram & - & 2 & 1 & 1 & 1 \\
\hline Clomazone + dimethachlor + napropamide & 1 & 1 & - & - & 1 \\
\hline Clomazone + metazachlor + napropamide & - & - & 1 & - & - \\
\hline Clomazone + metazachlor & 2 & 3 & 2 & 2 & 1 \\
\hline Clopyralid + picloram & 1 & 6 & 12 & 1 & 3 \\
\hline Dimethachlor + clomazone & 1 & 2 & 1 & 1 & - \\
\hline Dimethenamid-P + metazachlor + quinmerac & 2 & 1 & 4 & 1 & 1 \\
\hline Dimethenamid-P + metazachlor + clomazone & - & - & - & 1 & - \\
\hline Dimethenamid-P + quinmerac & - & 1 & 1 & - & 1 \\
\hline Dimethenamid-P + metazachlor & 1 & 3 & 2 & 1 & - \\
\hline Imazamox + quinmerac & 1 & 2 & 1 & - & 1 \\
\hline Imazamox + metazachlor & - & - & 1 & - & - \\
\hline Imazamox + metazachlor + quinmerac & 1 & 1 & 1 & - & 1 \\
\hline Metazachlor + quinmerac & 3 & 3 & 22 & 3 & 5 \\
\hline Napropamide + clomazone & - & 3 & 1 & - & - \\
\hline Pethoxamid + clomazone & 1 & 1 & 2 & - & 1 \\
\hline \multicolumn{6}{|c|}{ Łącznie - Total } \\
\hline $\begin{array}{l}\text { Liczba środków } \\
\text { Number of products }\end{array}$ & 146 & 201 & 297 & 51 & 108 \\
\hline $\begin{array}{l}\text { Liczba substancji czynnych } \\
\text { Number of active substances }\end{array}$ & 23 & 23 & 22 & 17 & 23 \\
\hline $\begin{array}{l}\text { Liczba grup chemicznych } \\
\text { Number of chemical groups }\end{array}$ & 13 & 13 & 12 & 10 & 12 \\
\hline
\end{tabular}

Źródło: opracowanie własne na podstawie rejestrów środków ochrony roślin z poszczególnych krajów oraz The Pesticide Manual

Source: own elaboration of plant protection products based on registered products from individual countries and The Pesticide Manual 
25 ogółem dostępnych substancji czynnych fungicydów, aż $36 \%$ stanowią substancje z grupy triazoli, do których należą: flutriafol, cyprokonazol, tetrakonazol, propikonazol, triadimenol, difenokonazol, metkonazol, tebukonazol i protiokonazol. Ostatnie 4 substancje stosowane są we wszystkich analizowanych krajach. Oprócz triazoli we wszystkich analizowanych krajach stosuje się również substancje z innych grup, takie jak: azoksystrobina, boskalid, dimoksystrobina, fluopyram, iprodion i pikoksystrobina. Substancje zarejestrowane we wszystkich krajach stanowią około 40\% substancji wymienionych w tabeli 1 . Pozostałe stosowane są jedynie w niektórych krajach, a część z nich tylko w jednym, i są to: bakteria Bacillus subtilis (Czechy), dimetomorf (Niemcy), flutriafol (Polska), karboksyna (Czechy), propikonazol (Czechy) i triadimenol (Niemcy). W ochronie rzepaku zastosowanie znajduje wiele fungicydów dwuskładnikowych, a najczęściej występujące połączenia, dostępne we wszystkich pięciu krajach to: azoksystrobina + tebukonazol, boskalid + dimoksystrobina, boskalid + metkonazol oraz tebukonazol + protiokonazol.

Dostępność substancji czynnych herbicydów przedstawia tabela 2. W Niemczech, Polsce, Czechach oraz na Słowacji odnotowano taką samą lub zbliżoną liczbę dostępnych substancji oraz grup chemicznych. Liczba mechanizmów działania była następująca: 9 (Niemcy, Polska), 8 (Czechy, Słowacja). Warto tutaj zauważyć, że różnice w liczbie zarejestrowanych środków są znacznie większe. Najmniej substancji czynnych o 7 różnych mechanizmach działania odnotowano na Litwie. Najczęściej rejestrowane substancje herbicydowe zarówno w Polsce, jak i krajach sąsiednich stanowią blisko 70\% ogółu dostępnych substancji, a są to: aminopyralid, chizalofop-P etylu, chizalofop-P tefurylu, chlomazon, chlopyralid, cykloksydym, dikwat, dimetachlor, glifosat, kletodym, metazachlor, napropamid, propachizafop, pikloram, dimetenamid-P i chinomerak. Pozostałe substancje zarejestrowane są do ochrony rzepaku w wybranych państwach. Tylko na Słowacji stosuje się S-metolachlor. Najczęściej rejestrowane połączenia substancji czynnych herbicydów dwu- lub trzyskładnikowych dostępne we wszystkich pięciu krajach to: chlomazon + metazachlor, chlopyralid + pikloram, dimetenamid-P + metazachlor + chinomerak oraz metazachlor + chinomerak.

Analizując dostępność herbicydów stwierdzono, że na 25 ogółem zarejestrowanych substancji chwastobójczych, $20 \%$ stanowią substancje z grupy pochodnych kwasu arylofenoksypropionowego (chizalofop-P etylu, chizalofop-P tefurylu, propachizafop, fluazyfop-P butylu, haloksyfop-P). Kolejne 20\% to substancje $\mathrm{z}$ grupy chloroacetamidów (dimetachlor, metazachlor, petoksamid, S-metolachlor, dimetenamid-P). Większość z nich, za wyjątkiem fluazyfopu-P butylu, haloksyfopu-P, petoksamidu i S-metolachloru, zarejestrowana jest we wszystkich analizowanych krajach.

Wśród insektycydów do ochrony rzepaku najwięcej substancji czynnych oraz ich grup chemicznych jest dostępnych w Czechach, nieznacznie mniej w Polsce i na
Słowacji, jeszcze mniej w Niemczech (gdzie areał rzepaku jest największy), a najmniej na Litwie. Pomimo zróżnicowania liczbowego w dostępności środków, liczba mechanizmów działania substancji insektycydowych w analizowanych krajach jest niewielka i zbliżona: 5 (Polska, Czechy), 4 (Niemcy, Litwa, Słowacja). W praktyce może to oznaczać ograniczenia w możliwości rotacji środków chemicznych i potencjalne problemy z rozwojem odporności, zwłaszcza słodyszka rzepakowego (Heimbach i wsp. 2006; Węgorek i wsp. 2009; Makūnas i wsp. 2011; Matyjaszczyk i wsp. 2015). Tę niekorzystną sytuację jeszcze bardziej uwydatnia fakt, że spośród 19 ogółem dostępnych substancji insektycydowych do ochrony rzepaku ponad 50\% stanowią substancje z jednej grupy chemicznej - pyretroidów: alfacypermetryna, beta-cyflutryna, cypermetryna, deltametryna, esfenwalerat, etofeproks, gamma-cyhalotryna, lambdacyhalotryna, tau-fluwalinat i zeta-cypermetryna. Większość z nich jest zarejestrowana we wszystkich analizowanych krajach (wyjątki to esfenwalerat, etofeproks i gamma-cyhalotryna). Oprócz pyretroidów we wszystkich pięciu krajach stosuje się: acetamipryd, indoksakarb oraz tiachlopryd. Łącznie, substancje stosowane we wszystkich pięciu krajach stanowią ponad 50\% ogółu substancji wymienionych w tabeli 3. Pozostałe substancje stosuje się rzadziej, jedynie w wybranych krajach. Fosmet jest przykładem substancji zarejestrowanej do ochrony rzepaku jedynie w Polsce. W ochronie insektycydowej stosowane są także środki dwuskładnikowe, a najczęściej rejestrowanym połączeniem jest deltametryna + tiachlopryd (Polska, Czechy, Słowacja, Litwa). W Niemczech do ochrony rzepaku nie są zarejestrowane insektycydy zawierajace dwie substancje czynne.

Analizując możliwości ochrony biologicznej rzepaku można zauważyć, że możliwa jest tylko ochrona przed patogenami i to jedynie w wybranych krajach. Dostępne są dwa grzyby: Coniothyrium minitans (Niemcy, Polska, Czechy, Słowacja) i Pythium oligandrum (Polska, Czechy, Słowacja) oraz jedna bakteria Bacillus subtilis (Czechy). Do ochrony przed szkodnikami i chwastami, w żadnym z analizowanych państw nie ma dostępnych środków biologicznych. Warto tutaj zaznaczyć, że integrowana ochrona roślin zachęca do stosowania metod biologicznych (Mrówczyński 2013).

Wiele zarejestrowanych do ochrony rzepaku substancji czynnych jest stosunkowo nowych, wprowadzonych do stosowania po roku 2000. Można wśród nich wymienić: boskalid, dimoksystrobinę, fluopyram, izopirazam, pikoksystrobinę, protiokonazol (fungicydy), aminopyralid, dimetenamid-P (herbicydy), gamma-cyhalotrynę, indoksakarb (insektycydy). Większość z nich za wyjątkiem izopirazamu i gamma-cyhalotryny jest zarejestrowana do ochrony rzepaku we wszystkich analizowanych państwach (Matyjaszczyk i Sobczak 2017a, b, c).

Tak duże zróżnicowanie dostępności środków ochrony roślin może dziwić w świetle faktu, że we wszystkich analizowanych krajach obowiązują identyczne przepisy unijne dotyczące dopuszczania środków ochrony roślin do obrotu 
Tabela 3. Insektycydy do ochrony rzepaku w Polsce i krajach sąsiadujących (zgodnie z danymi z kwietnia 2017)

Table 3. Insecticides for the protection of oilseed rape in Poland and neighboring countries (the data from April 2017)

\begin{tabular}{|c|c|c|c|c|c|}
\hline \multirow{2}{*}{$\begin{array}{l}\text { Substancje czynne } \\
\text { Active substances }\end{array}$} & \multicolumn{5}{|c|}{ Liczba środków - Number of products } \\
\hline & $\begin{array}{l}\text { Niemcy } \\
\text { Germany }\end{array}$ & $\begin{array}{l}\text { Polska } \\
\text { Poland }\end{array}$ & $\begin{array}{c}\text { Czechy } \\
\text { Czech Republic }\end{array}$ & $\begin{array}{l}\text { Litwa } \\
\text { Lithuania }\end{array}$ & $\begin{array}{l}\text { Słowacja } \\
\text { Slovakia }\end{array}$ \\
\hline Acetamiprid & 2 & 12 & 8 & 1 & 4 \\
\hline Alpha-cypermethrin & 1 & 13 & 4 & 1 & 5 \\
\hline Beta-cyfluthrin & 1 & 4 & 2 & 2 & 2 \\
\hline Cypermethrin & 3 & 6 & 4 & 1 & 5 \\
\hline Deltamethrin & 3 & 12 & 9 & 2 & 8 \\
\hline Esfevalerate & 2 & 1 & 1 & - & 1 \\
\hline Etofenprox & 1 & 1 & 2 & - & 1 \\
\hline Phosmet & - & 1 & - & - & - \\
\hline Gamma-cyhalothrin & 3 & - & 2 & - & 2 \\
\hline Chlorpyrifos & - & 21 & 4 & - & 5 \\
\hline Chlorpyrifos-methyl & - & - & 2 & - & 2 \\
\hline Indoxacarb & 1 & 2 & 1 & 1 & 1 \\
\hline Lambda-cyhalothrin & 12 & 18 & 12 & 2 & 4 \\
\hline Malathion & - & 1 & 1 & - & 1 \\
\hline Pymetrozine & 1 & 1 & 1 & 1 & - \\
\hline Pirimicarb & - & - & 7 & - & 1 \\
\hline Tau-fluvalinate & 1 & 2 & 1 & 1 & 1 \\
\hline Thiacloprid & 1 & 2 & 12 & 1 & 4 \\
\hline Zeta-cypermethrin & 2 & 6 & 8 & 1 & 3 \\
\hline Acetamiprid + lambda-cyhalothrin & - & 1 & - & - & - \\
\hline Beta-cyfluthrin + chlorpyrifos & - & 1 & - & - & 1 \\
\hline Cypermethrin + chlorpyrifos & - & 5 & 9 & - & 1 \\
\hline Cypermethrin + chlorpyrifos-methyl & - & 1 & 1 & - & - \\
\hline Deltamethrin + thiacloprid & - & 1 & 3 & 1 & 1 \\
\hline \multicolumn{6}{|c|}{ Łącznie - Total } \\
\hline $\begin{array}{l}\text { Liczba środków } \\
\text { Number of products }\end{array}$ & 34 & 112 & 94 & 15 & 53 \\
\hline $\begin{array}{l}\text { Liczba substancji czynnych } \\
\text { Number of active substances }\end{array}$ & 14 & 17 & 18 & 11 & 17 \\
\hline $\begin{array}{l}\text { Liczba grup chemicznych } \\
\text { Number of chemical groups }\end{array}$ & 4 & 5 & 6 & 4 & 5 \\
\hline
\end{tabular}

Źródło: opracowanie własne na podstawie rejestrów środków ochrony roślin z poszczególnych krajów oraz The Pesticide Manual Source: own elaboration of plant protection products based on registered products from individual countries and The Pesticide Manual

i stosowania (Rozporządzenie 2009; Matyjaszczyk i Sobczak 2017d).

\section{Wnioski / Conclusions}

$\mathrm{Na}$ podstawie analizy środków zarejestrowanych do ochrony rzepaku w Polsce i państwach sąsiednich można stwierdzić, że:

1. Liczba zarejestrowanych środków ochrony roślin jest bardzo zróżnicowana $\mathrm{W}$ analizowanych państwach i nie jest powiązana $z$ areałem uprawy. W Polsce do- stępnych jest najwięcej insektycydów, a w Czechach najwięcej fungicydów oraz herbicydów. Najmniejszą liczbę preparatów z każdej grupy odnotowano na Litwie. Jednocześnie największy areał rzepaku jest w Niemczech, a najmniejszy na Słowacji.

2. Tylko część dostępnych substancji czynnych (40\% fungicydów, około $70 \%$ herbicydów, około 50\% insektycydów) jest stosowana we wszystkich pięciu analizowanych państwach. W każdej grupie środków są substancje zarejestrowane tylko w jednym państwie.

3. W wszystkich analizowanych krajach zarejestrowane są fungicydy oraz herbicydy zawierające dwie lub 
trzy substancje czynne różniące się mechanizmem działania. Udział takich formulacji stanowi około $30 \%$ w grupie fungicydów oraz około $15 \%$ wśród herbicydów. W Niemczech brak jest zarejestrowanych insektycydów dwuskładnikowych, a w pozostałych analizo- wanych krajach ich udział stanowi około 10\% ogółu dostępnych preparatów owadobójczych.

4. Na Litwie brak środków pochodzenia biologicznego do ochrony rzepaku, a w pozostałych krajach ich dostępność jest niewielka. Zarejestrowane są jedynie fungicydy oparte na działaniu grzybów lub bakterii.

\section{Literatura / References}

Barzman M., Barberi P., Birch A.N.E., Boonekamp P., Dachbrodt-Saaydeh S., Graf B., Hommel B., Jensen J.E., Kiss J., Kudsk P., Lamichhane J.R., Messéan A., Moonen A.-C., Ratnadass A., Ricci P., Sarah J.-L., Sattin M. 2015. Eight principles of integrated pest management. Agronomy for Sustainable Development 35 (4): 1199-1215. DOI: 10.1007/s13593-015-0327-9.

BVL - Bundesamt für Verbraucherschutz und Lebensmittelsicherheit, Verzeichsnis Zugelassener Pflanzenschutzmittel - Standardsuche 2017. https://apps2.bvl.bund.de/psm/jsp/index.jsp?modul=form [Accessed: 15.04.2017].

Eurostat 2017. Crop Statistics. http://ec.europa.eu/eurostat/data/database [Accesed: 25.07.2017].

GUS 2016. Rocznik Statystyczny Rolnictwa. Główny Urząd Statystyczny, Warszawa, 460 ss. ISSN 2080-8798.

Heimbach U., Müller A., Thieme T. 2006. First steps to analyse pyrethroid resistance of different oilseed rape pests in Germany. Nachrichtenblatt für den Pflanzenschutz 58 (1): 1-5.

Jajor E., Mrówczyński M. (red.). 2013. Metodyka integrowanej ochrony rzepaku ozimego i jarego dla producentów. Instytut Ochrony Roślin - PIB, Poznań, 65 ss. ISBN 978-83-89867-89-6.

Makūnas V., Brazauskienė I., Šmatas R. 2011. Resistance of Meligethes aeneus to pyrethroids in Lithuania. Žemdirbystė=Agriculture 98 (4): 431-438.

Matyjaszczyk E., Sobczak J., Szulc M. 2015. Is the possibility of replacing seed dressings containing neonicotinoids with other means of protection viable in major Polish agricultural crops? Journal of Plant Protection Research 55 (4): 329-335. DOI: 10.1515/jppr-20150056 .

Matyjaszczyk E., Sobczak J. 2017a. Nowe substancje aktywne herbicydów stosowane w Polsce. Przemysł Chemiczny 96 (1): $245-247$. DOI: $10.15199 / 62.2017 .1 .31$.

Matyjaszczyk E., Sobczak J. 2017b. Nowe substancje aktywne fungicydów stosowane w Polsce. Przemysł Chemiczny 96 (6): $1407-1409$. DOI: $10.15199 / 62.2017 .6 .39$.

Matyjaszczyk E., Sobczak J. 2017c. Nowe substancje aktywne insektycydów stosowane w Polsce. Przemysł Chemiczny 96 (6): $1367-$ 1369. DOI: $10.15199 / 62.2017 .6 .30$.

Matyjaszczyk E., Sobczak J. 2017d. Is the EU law leading to harmonization in availability of plant protection products? A case study from oilseed rape and potato in 5 member states. Crop Protection 100: 73-76.

Mrówczyński M. (red.). 2013. Integrowana ochrona upraw rolniczych. Podstawy integrowanej ochrony. t. 1. PWRiL, Poznań, 153 ss.

MRiRW - Ministerstwo Rolnictwa i Rozwoju Wsi 2017. Wyszukiwarka środków ochrony roślin. https://bip.minrol.gov.pl/InformacjeBranzowe/Produkcja-Roslinna/Ochrona-Roslin/Wyszukiwarka-srodkow-ochrony-roslin [dostęp: 15.04.2017].

Rosiak E. 2014. Krajowy rynek rzepaku na tle rynku światowego. Zeszyty Naukowe Szkoły Głównej Gospodarstwa Wiejskiego w Warszawie. Problemy Rolnictwa Światowego 14 (29) (1): 86-96.

Rozporządzenie Parlamentu Europejskiego i Rady (WE) nr 1107/2009 z dnia 21 października 2009 r. dotyczące wprowadzania do obrotu środków ochrony roślin i uchylające dyrektywy Rady 79/117/EWG i 91/414/EWG, OJ L 309/1.

The Pesticide Manual 2012. Sixteen Edition (C. MacBean, ed.). BCPB, 1440 pp.

The State Plant Service under the Ministry of Agriculture 2017. Plant protection products authorisation division. http://www.vatzum.lt/lt/ veikla/veiklos-sritys/augalu-apsaugos-produktu-registravimas/\#raap [Accessed: 15.04.2017].

ÚKSÚP - Ústredný kontrolný a skúšobný ústav pol'nohospodársky v Bratislave, Prípravky na ochranu rastlín. 2017. Zoznam autorizovaných prípravkov. http://www.uksup.sk/orp-pripravky-na-ochranu-rastlin-registre-a-zoznamy/ [Accessed: 15.04.2017].

ÚKZÚZ - Ústřední kontrolní a z kušební ústav zemědělský. Registr př́ipravků na ochranu rostlin. 2017. http://eagri.cz/public/app/eagriapp/POR/Vyhledavani.aspx?type $=0 \&$ vyhledat=A\&stamp=1438154442628 [Accessed: 15.04.2017].

Węgorek P., Mrówczyński M., Zamojska J. 2009. Resistance of pollen beetle (Meligethes aeneus F.) to selected active substances on insecticides in Poland. [Odporność słodyszka rzepakowego (Meligethes aeneus F.) na wybrane substancje aktywne insektycydów w Polsce]. Journal of Plant Protection Research 49 (1): 119-127. 